\title{
Bighorn Basin Coring Project (BBCP): a continental perspective on early Paleogene hyperthermals
}

\author{
W. C. Clyde ${ }^{1}$, P. D. Gingerich ${ }^{2}$, S. L. Wing ${ }^{3}$, U. Röhl ${ }^{4}$, T. Westerhold ${ }^{4}$, G. Bowen ${ }^{5}$, K. Johnson ${ }^{6}$, \\ A. A. Baczynski ${ }^{7}$, A. Diefendorf ${ }^{8}$, F. McInerney ${ }^{9}$, D. Schnurrenberger ${ }^{1}$, A. Noren ${ }^{10}$, K. Brady ${ }^{10}$, and \\ the BBCP Science Team \\ ${ }^{1}$ Department of Earth Sciences, University of New Hampshire, 56 College Rd., Durham, NH 03824, USA \\ ${ }^{2}$ Department of Earth and Environmental Sciences and Museum of Paleontology, University of Michigan, \\ Ann Arbor, MI 48109, USA \\ ${ }^{3}$ Department of Paleobiology, Smithsonian Museum of Natural History, 10th Street and Constitution Avenue, \\ NW, Washington, DC 20560, USA \\ ${ }^{4}$ MARUM - Center for Marine Environmental Sciences, University of Bremen, Leobener Strasse, \\ 28359 Bremen, Germany \\ ${ }^{5}$ Department of Geology \& Geophysics, University of Utah, Salt Lake City, UT 84112, USA \\ ${ }^{6}$ Smithsonian Museum of Natural History, 10th Street and Constitution Avenue, NW, \\ Washington, DC 20560, USA \\ ${ }^{7}$ Department of Earth and Planetary Sciences, Northwestern University, Evanston, IL 60208, USA \\ ${ }^{8}$ Department of Geology, University of Cincinnati, Cincinnati, OH 45221, USA \\ ${ }^{9}$ School of Earth \& Environmental Sciences, University of Adelaide 5005, Australia \\ ${ }^{10}$ LacCore, University of Minnesota, Minneapolis, MN 55455, USA \\ Correspondence to: W. C. Clyde (will.clyde@unh.edu)
}

Received: 22 July 2013 - Accepted: 25 September 2013 - Published: 5 November 2013

\begin{abstract}
During the summer of 2011, the Bighorn Basin Coring Project (BBCP) recovered over $900 \mathrm{~m}$ of overlapping core from 3 different sites in late Paleocene to early Eocene fluvial deposits of northwestern Wyoming. BBCP cores are being used to develop high-resolution proxy records of the Paleocene-Eocene Thermal Maximum (PETM) and Eocene Thermal Maximum 2 (ETM2) hyperthermal events. These events are short-term, large magnitude global warming events associated with extreme perturbations to the earth's carbon cycle. Although the PETM and ETM2 occurred 55-52 million years ago, they are analogous in many ways to modern anthropogenic changes to the carbon cycle. By applying various sedimentological, geochemical, and palynological methods to the cores, we hope to better understand what caused these events, study the biogeochemical and ecological feedbacks that operated during them, and reveal precisely how they impacted continental environments.

Core recovery was $>98 \%$ in all holes and most drilling was carried out without fluid additives, showing that continuous coring of continental smectitic deposits like these can be achieved with minimal risk of contamination to molecular biomarkers. Cores were processed in the Bremen Core Repository where the science team convened for 17 days to carry out data collection and sampling protocols similar to IODP projects. Initial results show that the weathered horizon extends to as much as $\sim 30 \mathrm{~m}$ below the surface and variations in magnetic susceptibility within the cores record an interplay between grain size and pedogenesis. Previous investigations of outcrops near the BBCP drill sites allow detailed evaluation of the effects of weathering on common proxy methods. Studies of lithofacies, organic geochemistry, stable isotope geochemistry, calibrated XRF core scanning, paleomagnetics, and palynology are underway and will represent the highest resolution and most integrated proxy records of the PETM from a continental setting yet known. An extensive outreach program is in place to capitalize on the educational value associated with the Bighorn Basin's unusually complete record of Phanerozoic earth history.
\end{abstract}




\section{Background and motivation}

The early Paleogene was a particularly dynamic period of earth history. It began with the physical and biological events surrounding the $\mathrm{K} / \mathrm{Pg}$ boundary (i.e., bolide impact, mass extinction) and progressed into an unusually warm climate state, where global mean annual temperatures were as much as $10^{\circ} \mathrm{C}$ higher than today and $\mathrm{CO}_{2}$ concentrations may have been $>1000 \mathrm{ppm}$. Superimposed on these long-term changes were a series of short-term, potentially orbitally paced, extreme global warming events known as "hyperthermals". The Paleocene-Eocene Thermal Maximum (PETM), the largest magnitude and best studied hyperthermal, is characterized by a global temperature rise of $5-9^{\circ} \mathrm{C}$ in less than $10 \mathrm{kyr}$ and an input of up to $4500 \mathrm{Gt}$ of carbon into the mixed ocean-atmosphere carbon pool (Thomas et al., 2002; Wing et al., 2005; Zachos et al., 2005; Sluijs et al., 2006). The PETM lasted $\sim 170000 \mathrm{yr}$ and is associated with major changes to atmospheric moisture transport, restructuring of global ocean circulation, triggering of high-latitude intercontinental mammalian dispersal, extinction of $35-50 \%$ of deep-sea benthic foraminifera species, mammalian dwarfing, and significant poleward range extensions of continental floras (see reviews by Bowen et al., 2006; Gingerich, 2006; Sluijs et al., 2007; McInerney and Wing, 2011). Although the PETM represents one of the most profound perturbations to the earth system in the last 100 million years, its cause remains unknown with several competing hypotheses being debated. Recent focus of this interval by the deep-sea coring community has established the existence of other, smaller amplitude, carbon cycle perturbations during the Paleogene that mimic the PETM (Thomas and Zachos, 2000; Lourens et al., 2005; Thomas et al., 2006; Agnini et al., 2009; Sexton et al., 2011). These other hyperthermals suggest that the PETM was not a unique event and that short-term, high-amplitude changes to the carbon cycle may be part of natural earthsystem variability during greenhouse periods like the early Paleogene.

Understanding the causes and effects of these hyperthermals is particularly important for gaining perspective on the response of the earth system to current anthropogenic changes to the carbon cycle. For instance, the amount of carbon release at the PETM is roughly similar to what is projected for anthropogenic fossil fuel release (Zeebe and Zachos, 2013). However, unlike modern climate change that is just beginning, we can study what happened before, during, and after the PETM. Having a natural analog to the Anthropocene is valuable for informing predictions of future climate change and teaching the public about the dynamic and coupled processes that comprise the earth system. It is also possible that current global warming could trigger a hyperthermallike feedback not currently accounted for in global climate models, which means that current predictions for future climate change may be substantially underestimated.

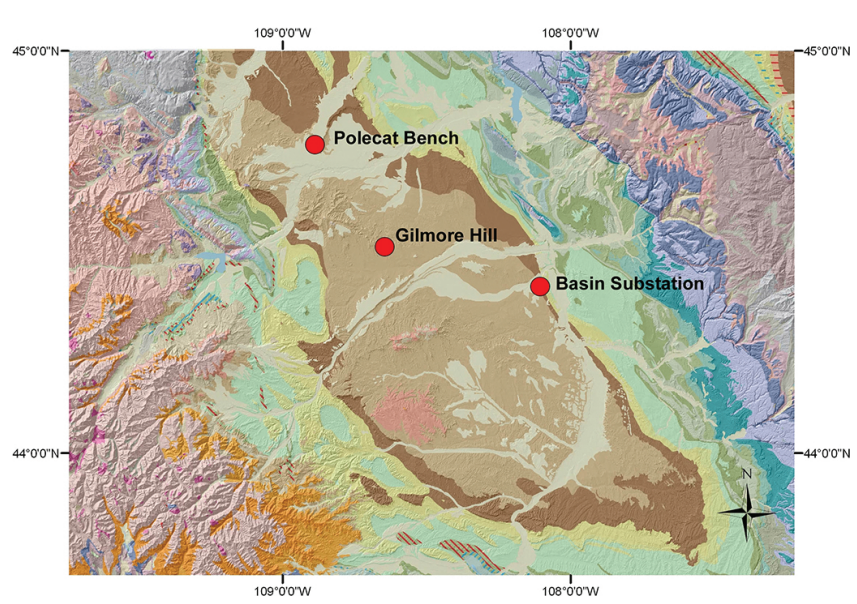

Figure 1. Geological map of Bighorn Basin, Wyoming, showing location of the drill sites associated with the BBCP. Dark brown represents the upper Paleocene Fort Union Formation and light brown represents the lower Eocene Willwood Formation which are the units drilled during the $\mathrm{BBCP}$.

We undertook a targeted scientific drilling project in the Bighorn Basin, Wyoming, to recover continuous continental sedimentary records of the PETM and Eocene Thermal Maximum 2 (ETM2), a smaller magnitude hyperthermal that occurred $\sim 2$ My after the PETM (Fig. 1). During the Late Cretaceous-early Paleogene Laramide orogeny, the Bighorn Basin experienced rapid tectonic subsidence while adjacent mountain ranges were being uplifted. This combination of abundant accommodation space and high sediment flux from the erosion of the adjacent uplifts, led to the development of a very complete and expanded early Paleogene fluviallacustrine stratigraphic record for this time interval. Average sediment accumulation rates are on the order of 0.25 $0.50 \mathrm{~m} \mathrm{kyr}^{-1}$, which translates into a $\sim 50$-meter-thick PETM interval. Fossils, especially vertebrates and plants, are abundant in the early Paleogene Bighorn Basin deposits and have been intensely studied for over a century (Gingerich, 1980; Bown et al., 1994; Wing et al., 1998; Gingerich and Clyde, 2001). Stratigraphic studies incorporating paleontological, sedimentological, and paleoclimatic data have been common for decades, with recent focus on hyperthermals (Koch et al., 1992; Clyde and Gingerich, 1998; Bowen et al., 2001; Wing et al., 2005; Gingerich, 2006; Secord et al., 2010; Abels et al., 2013). These studies, however, have been limited to sampling discontinuous exposures of weathered outcrops. By coring these sediments, we were able to collect continuous stratigraphic records of fresh, unweathered material of the PETM and ETM2 hyperthermals. By sampling these cores at highresolution (1000-10000 yr sampling interval), we can develop multi-proxy records for temperature, carbon cycling, and biotic change that will allow us to investigate, in an unprecedented way, the high-frequency climatic and biotic variability of a continental depositional system during greenhouse conditions. 


\section{Scientific goals and questions}

Despite over a decade of intense research, many questions still remain concerning the causes and effects of hyperthermals. Although it is generally agreed that hyperthermals represent the geologically rapid injection of isotopically light carbon into the mixed ocean-atmosphere system, there is still no consensus as to the source(s) of this carbon and whether the PETM and other hyperthermals represent a continuum of the same process or represent fundamentally different processes (Sexton et al., 2011). We hope to use the continuous and expanded multi-proxy records of hyperthermals from the BBCP to better constrain the tempo and mode of associated changes in the carbon cycle, climate, ecosystem, and hydrology in this continental environment in an effort to better understand their causes and consequences. To focus the $\mathrm{BBCP}$ research, a series of guiding scientific questions were developed during the planning workshops leading up to the drilling. These include

- Can the internal carbon isotopic variability before, within, and after the PETM and ETM2 be used to correlate between terrestrial and marine records and does it reveal clues about the cause of these hyperthermals?

- Are there observable lags between the carbon isotope excursions (CIEs) and other paleoenvironmental indicators (e.g., temperature, precipitation, biomarkers, pollen)?

- Is ETM2 characterized by similar biotic changes as seen at the PETM?

- How are floral and faunal changes related during hyperthermals? Do faunas respond to floral change or vice versa?

- How did the PETM and other hyperthermals affect the hydrological cycle (e.g., monsoonal circulation) in the Rocky Mountain region?

- How did changes in the flora and changes in the hydrological cycle impact wildfire activity?

- What was the continental sedimentary response to the PETM and other hyperthermals (e.g., effects on pedogenesis)?

- Are the facies stacking patterns or geochemical records (e.g., XRF) in the Bighorn Basin cyclic?

- If these records show cyclicity, are the periods of those cycles consistent with predictions for astronomical control?

- If astronomically controlled, do the dominant periodicities change through the sequence and is there a relationship of this to the PETM or other hyperthermals?

\section{Drilling summary}

A BBCP Drilling Plan was developed during a series of meetings starting with a workshop in Powell, Wyoming, in June 2007 and culminating with a proposal to NSF in 2009 that was funded in October of 2010. After a final pre-drilling planning meeting at the Denver Museum of Nature and Science (DMNS) in March 2011, drilling began in July 2011 and was completed in August 2011. Drilling was carried out by Ruen Drilling, Inc. and down hole logging (magnetic susceptibility, resistivity, density, gamma, caliper) was done by Colog. Coring was carried out with a truck mounted HQ coring system $(6.2 \mathrm{~cm}$ diameter) and cores were captured in a thin transparent Lexan liner. This protocol was used to mimic, as closely as possible, the IODP coring protocol because the BBCP cores were processed, logged for physical properties, XRF scanned, and archived in the Bremen Core Repository which also serves as one of the three IODP core repositories. Three sites were drilled, with two overlapping holes at each site.

\subsection{Basin Substation}

This site was chosen because outcrops in the area indicate that the PETM is preserved in a relatively organic-rich package of sediments here but the exposures are too poor for good surface sampling. Most PETM lithofacies in the Bighorn Basin are quite oxidized and thus very low in total organic matter so do not preserve abundant palynomorphs or biomarkers, both of which we hope to recover in the BBCP. By targeting the PETM sediment package at Basin Substation, we aim to maximize organic preservation so these methods can be successfully applied.

Coring at Basin Substation occurred between 13 and 17 July 2011 and two overlapping cores were drilled. One core (BBCP-BSN11-1A) was drilled to $138.4 \mathrm{~m}$ below surface (mbs) and the second core (BBCP-BSN11-1B) was drilled to $138.6 \mathrm{mbs}$ (Table 1; Fig. 2). Both cores were drilled using only municipal water, thus minimizing potential organic contamination. Down hole geophysical logs were recovered to about $100 \mathrm{~m}$ depth.

\subsection{Polecat Bench}

Polecat Bench is the best documented continental record of the PETM known in the world. It is the site where (a) the oldest North American Artiodactyla, Perissodactyla, and true Primates defining the Paleocene-Eocene boundary were first found (Gingerich, 1989), (b) conspicuous dwarfing of mammals was first documented (Gingerich, 1989; Clyde and Gingerich, 1998), (c) the PETM carbon isotope anomaly was first found on land (Koch et al., 1992) and studied at highresolution (Bowen et al., 2001) and (d) the CIE in organic carbon was first compared to that in paleosol carbonate (Magioncalda et al., 2004). Paleosols here have been studied 
Table 1. Summary data for BBCP drilling sites.

\begin{tabular}{|c|c|c|c|c|c|c|c|c|}
\hline Locality & Drill hole & Lat $(\mathrm{N})$ & Lon $(\mathrm{W})$ & $\begin{array}{l}\text { Elev. } \\
(\mathrm{m})\end{array}$ & $\begin{array}{r}\text { Depth } \\
(\mathrm{m})\end{array}$ & $\begin{array}{r}\text { Core recovery } \\
(\%)\end{array}$ & Fluid & Target \\
\hline Basin Substation & BBCP-BSN11-1A & 44.4162583 & 108.1055664 & 1240.5 & 138.4 & 100.0 & Municipal Water & PETM \\
\hline Basin Substation & BBCP-BSN11-1B & 44.4162042 & 108.1053154 & 1244.2 & 138.6 & 98.6 & Municipal Water & PETM \\
\hline Polecat Bench & BBCP-PCB11-2A & 44.7688571 & 108.8879668 & 1588.1 & 130.0 & 99.0 & Municipal Water & PETM \\
\hline Polecat Bench & BBCP-PCB11-2B & 44.7688782 & 108.8878902 & 1589.4 & 245.1 & 100.0 & Bentonite + Polymer & PETM \\
\hline Gilmore Hill & BBCP-GMH11-3A & 44.5159525 & 108.6459393 & 1521.8 & 202.4 & 98.8 & Municipal Water & Elmo/H2 \\
\hline Gilmore Hill & BBCP-GHM11-3B & 44.5158935 & 108.6459018 & 1521.8 & 66.7 & 98.4 & Municipal Water & Elmo/H2 \\
\hline
\end{tabular}
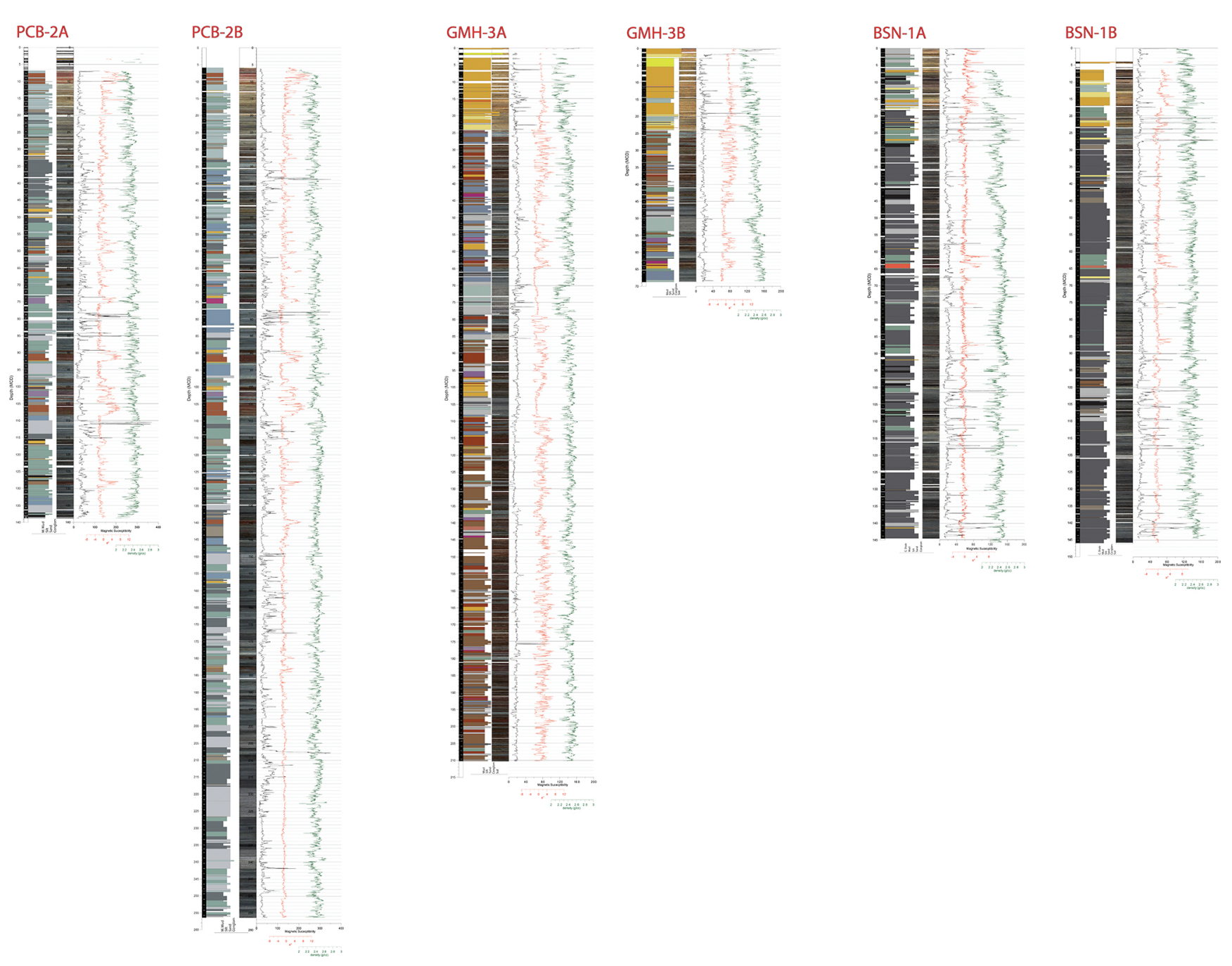

Figure 2. Lithological logs, line-scan images, magnetic susceptibility (black curves), color redness index a* (red curves), density (green curves) for each of the cores drilled during the BBCP. Cores are arrayed northwest (left) to southeast (right; see Fig. 1). PCB - Polecat Bench; GMH - Gilmore Hill; BSN - Basin Substation.

in detail from surrounding surface sections providing a 3dimensional lithostratigraphy that can be correlated to the core records, thus linking these previous outcrop studies to the new core studies. Furthermore, the first attempt to recognize orbital cyclicity in a continental PETM section was done using a Polecat Bench surface section (Abdul-Aziz et al., 2008) so cores from here will provide an excellent mechanism to test, and expand on, that work.

From 18 to 25 July 2011 two overlapping cores were drilled at Polecat Bench. One core (BBCP-PCB11-2A) was drilled to $130.0 \mathrm{mbs}$ and the second core (BBCP-PCB11-2B) to $245.1 \mathrm{mbs}$ (Table 1; Fig. 2). The first core was drilled using 
only municipal water and the second was drilled with bentonite and polymer additives to stabilize the hole and maximize drilling depth and core recovery. Downhole geophysical logs were recovered for the entire $245 \mathrm{~m}$ of the second (B) hole.

\subsection{Gilmore Hill}

Outcrops in the Gilmore Hill area record one of the most complete sections that spans the Wa-4/Wa-5 biozone boundary (= "Biohorizon B") which is the largest mammalian turnover in the early Eocene after the PETM (Schankler, 1980; Chew, 2009). Recent isotopic sampling of surface sections in this area has also established the existence of an isotopic excursion that correlates to the ETM2/H2 interval (Abels et al., 2012). By retrieving core records from here, we hope to apply the various methods outlined above to better document the continental effects of non-PETM hyperthermals, further constrain their cause, and compare them to records of the PETM. Only by comparing detailed multiproxy records of multiple hyperthermals will it be possible to determine whether they share a common cause and whether they result in repeated, and thus predictable, environmental changes.

From 1 to 5 August 2011 two overlapping cores were drilled at Gilmore Hill. One core (BBCP-GMH11-3A) was drilled to $202.4 \mathrm{mbs}$ and the second core (BBCP-GMH113B) was drilled to $66.7 \mathrm{mbs}$ (Table 1; Fig. 2). Both cores were drilled using only municipal water and downhole geophysical logs were recovered for $89 \mathrm{~m}$ in the first hole and the entire $66 \mathrm{~m}$ of the second hole.

\section{Core analysis and post-drilling science}

After preliminary cataloging and describing of the $\mathrm{BBCP}$ cores in the field, they were shipped to the Bremen Core Repository (BCR) in a refrigerated container on 10 August 2011, where they arrived on 27 September 2011. We decided to utilize the BCR for a variety of reasons; two of the BBCP senior personnel (Röhl and Westerhold) are from the MARUM (University of Bremen), the BCR and adjacent MARUM laboratories have excellent core processing facilities and support staff, and it is the repository for several important PETM cores drilled in the Atlantic and Arctic Oceans (ODP and IODP). The BBCP science team converged at the BCR from 8 to 27 January 2012, to split, describe, scan, sample, and archive the cores. A BBCP Sample, Data and Obligations Policy ${ }^{1}$ was developed and distributed before this meeting to ensure that the roles and responsibilities of scientists interested in working on the BBCP were clearly communicated ahead of time. The BBCP policy is strongly based on the equivalent IODP policy and includes a one-year data moratorium during which science team members have

\footnotetext{
${ }^{1}$ http://earth.unh.edu/clyde/pdfs/BBCP_Sample_Policy.pdf
}

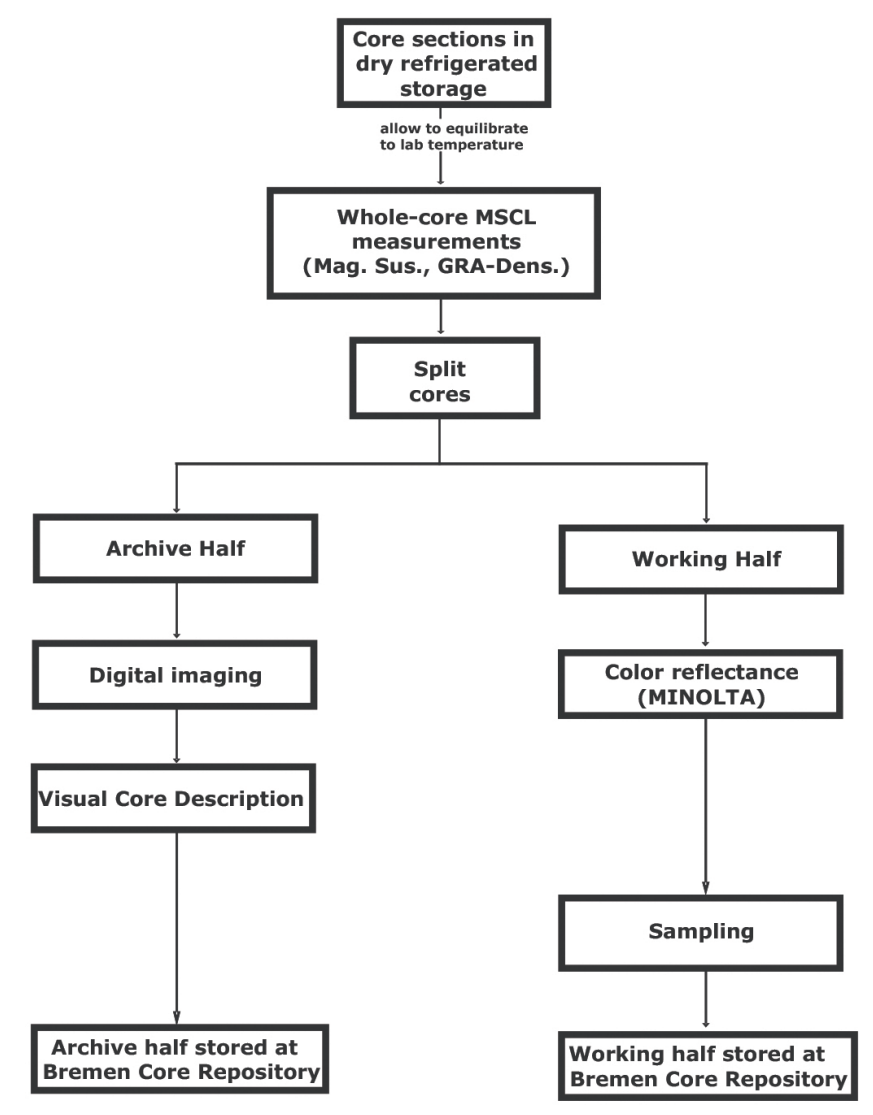

Figure 3. Work flow used to process BBCP cores at the Bremen Core Repository.

exclusive rights of access to $\mathrm{BBCP}$ material (core samples and data). After the one-year moratorium, non-BBCP science team investigators can make sample and data requests to the BBCP Sample Allocation Committee (SAC, consisting of WC, PG, SW, and UR).

For the sampling and data acquisition meeting at the BCR, we modeled our core flow scheme after IODP and ICDP procedures (Fig. 3). Whole-core MSCL measurements (magnetic susceptibility [MS], gamma ray attenuation [GRA] density) were performed at MARUM on a GEOTEK MultiSensor Core Logger (MSCL) before the science team arrived. During the meeting, cores were split with a water cooled diamond tipped core saw which worked well despite the existence of smectitic clays in the core materials. After splitting, the working halves were color scanned using a Minolta Spectrophotometer $2600 \mathrm{~d}$ and then sampled before being archived in the refrigerated core storage facility at the BCR. Sampling was based on formal sample requests that were submitted by the science team before the meeting with stratigraphic resolution and sampling protocols varying depending on the sample type. Over 4500 samples were collected including samples for carbonate nodules, bulk organic carbon, paleomagnetism, vertebrate fossils, palynology, biomarkers, plant 
Table 2. Summary tally of samples from the BBCP initial sampling meeting.

\begin{tabular}{lrrrrrrr}
\hline & \multicolumn{7}{c}{ Drill hole } \\
\cline { 2 - 6 } Sample type & BSN 1A & BSN 1B & PCB 2A & PCB 2B & GMH 3A & GMH 3B & Total \\
\hline Carbonate nodules & 3 & 4 & 186 & 339 & 266 & 44 & 842 \\
Bulk organic carbon & 0 & 322 & 241 & 176 & 268 & 12 & 1019 \\
Paleomagnetism & 80 & 0 & 0 & 148 & 138 & 0 & 366 \\
Vertebrate fossils & 0 & 1 & 0 & 0 & 1 & 0 & 2 \\
Palynology & 0 & 296 & 214 & 170 & 238 & 0 & 918 \\
Biomarkers & 0 & 225 & 188 & 131 & 209 & 24 & 777 \\
Plant cuticle & 33 & 0 & 0 & 5 & 1 & 4 & 43 \\
Sediment (grain size, XRF) & 155 & 72 & 56 & 72 & 296 & 0 & 651 \\
\hline Total & 271 & 920 & 885 & 1041 & 1417 & 84 & 4618 \\
\hline
\end{tabular}

cuticle, and bulk sediment for grain size and XRF analysis (Table 2). The archive halves of the cores were line scanned using a 3 CCD digital image device attached to the SuperSlit XRF-core scanner. These line-scans produce visual color images and generate color data in RGB and CIE space that can be used to calculate commonly used color indices (e.g., $\left.L^{*}, a^{*}, b^{*}\right)$. After line scanning, archive halves were visually described. Original handwritten description forms (Visual Core Descriptions-VCDs) were scanned to PDF, compiled for each hole, and archived. Basic lithological data were extracted from the VCDs and entered into a searchable lithological database before archiving the cores in the BCR. All data are stored in the ExpeditionDIS especially configured for this project, and for the science team members, in a loginprotected data sharing web site (http://www.PBWorks.com).

In order to address the central BBCP science questions, the science team is applying a variety of different methodological approaches to the cores. XRF scanning of the archive halves of the cores is being carried out to evaluate patterns of variability in bulk geochemistry and determine whether these continental facies may record orbital cycles. To track changes in the carbon cycle and climate, and to correlate the cores to other terrestrial and marine records of hyperthermals, stable carbon and oxygen isotopes of paleosol nodules and bulk organic matter are being analyzed. Palynological analysis is the primary in situ tool for tracking ecological changes through time, although correlations to nearby outcrops with vertebrate and plant macro fossils are also important. Preliminary tests carried out on cuttings from a pilot drill hole near the Basin Substation site during 2007 indicated that subsurface samples had greater diversity and higher abundance of molecular biomarkers than samples collected from subaerially exposed outcrops so sampling was carried out on all of the cores in hopes of recovering biomarkers that can be informative about temperature change and ecological change (plant and microbial lipids, including alkanes, terpenoids, and hopanes). Patterns of change in wildfire activity have been proposed as a consequence of PETM climate change so BBCP cores were sampled for analysis of polycyclic aromatic hydrocarbons (PAHs) and for charcoal as proxies for wildfire activity. Paleomagnetic samples were collected to confirm the basic magnetic polarity stratigraphy observed from the overlapping outcrop record and to investigate potential geomagnetic and/or rock magnetic changes across the hyperthermals as have been reported elsewhere (Kopp et al., 2007; Lippert and Zachos, 2007; Schumann et al., 2008; Lee and Kodama, 2009). Certain parts of the cores with higher concentrations of organic carbon were sampled for plant cuticle in hopes of reconstructing $p \mathrm{CO}_{2}$. Grain size measurements and XRF analysis of bulk sediment samples were carried out to investigate patterns of lithological change across the hyperthermals and to help calibrate the XRF scanning data. Two vertebrate fossils were discovered in BBCP cores so these were collected for archiving at the University of Michigan Museum of Paleontology, where most of the vertebrate collections from nearby outcrops are located.

\section{Initial results}

One of the more important preliminary observations from the project is the relatively deep weathering horizons that were encountered. Although we knew that weathering depths were below the level that is practical to access by digging surface outcrops, we did not have a firm absolute estimate of them in this type of "badland" erosional environment. Assessment of the VCDs, line-scan images, and color data indicate that obvious weathering features (e.g., oxidation, hydration, fracturing) extend down $\sim 20-30 \mathrm{~m}$ below the surface at all three drill sites (Fig. 4). The oxidation and hydration reactions most clearly impact the color of the cores, where the color index $\mathrm{a}^{*}$ (redness/greenness) trends toward higher values (redder and yellower) in the weathered zone (Fig. 2). For instance, the bright red color of the paleosol bed at the top of the Polecat Bench cores (7-10 mcd, Fig. 4) is clearly accentuated by weathering compared to the muted red hues of the unweathered paleosols lower in the core (e.g., $57-59 \mathrm{mcd}$, Fig. 4). The Gilmore Hill cores seem to show the deepest weathering horizons, probably due to the $\sim 20 \mathrm{~m}$ of poorly 


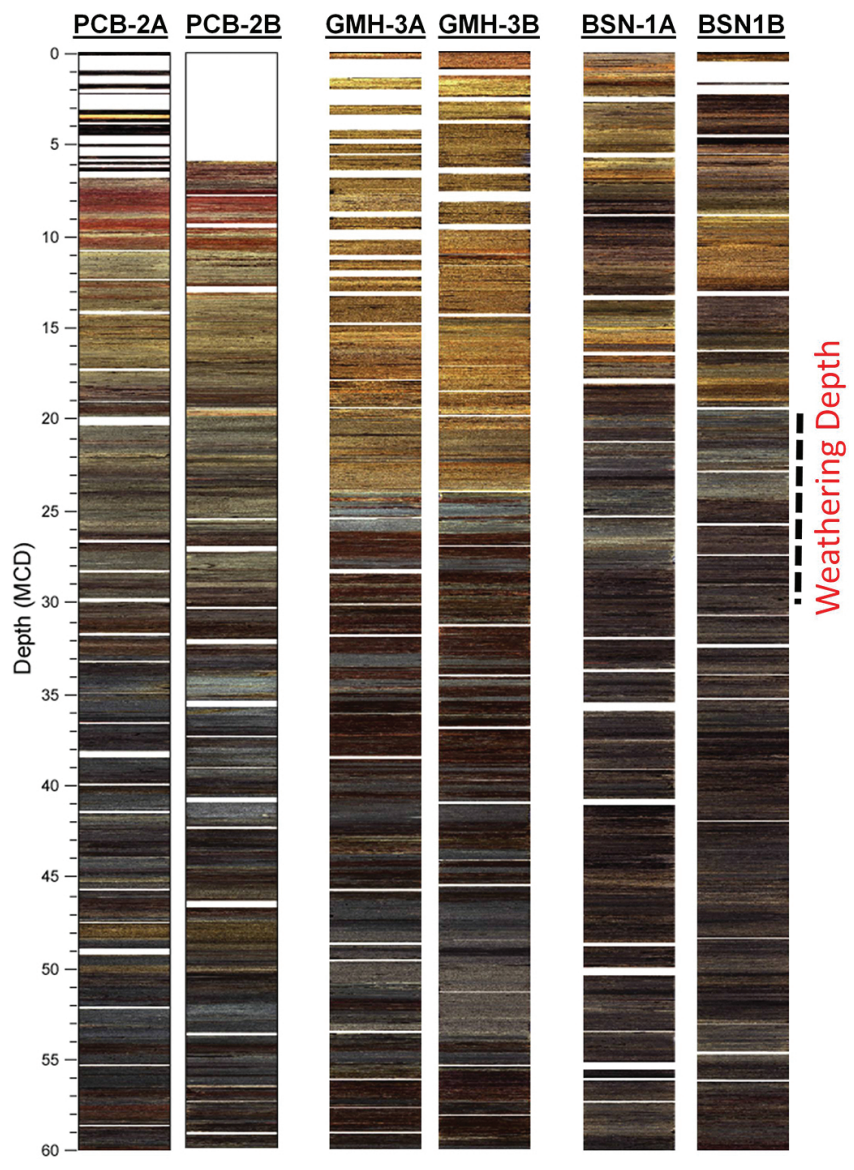

Figure 4. Line-scan images of the upper $60 \mathrm{~m}$ from each of the BBCP cores. Weathering depths of $\sim 20-30 \mathrm{~m}$ are clear in the change from yellowish colors near the surface to drabber colors in the subsurface. Depth is scaled in meters composite depth (MCD).

cemented sandstone that lies at the tops of those cores, creating a highly permeable conduit for meteoric water to infiltrate downwards. The BBCP cores may provide an excellent natural laboratory to investigate the "critical zone" at the interface between the atmosphere and the lithosphere in this kind of erosional sedimentary environment.

Comparison of the lithological logs based on the VCDs with the logs of magnetic susceptibility, density, and color indicates several general patterns (Fig. 2). Below the weathered zone, color variations as expressed by the color index $\mathrm{a}^{*}$ highlight the presence and frequency of reddish colored paleosols. These are important marker beds that can be used to correlate the cores to surface outcrops and thus provide key links to the previously published stratigraphic records from these areas. The Polecat Bench B core clearly shows the up-section increase in frequency of paleosol red beds that marks the Paleocene-Eocene boundary interval in the Bighorn Basin. The Basin Substation cores show relatively few red paleosols across the same interval, highlighting the less oxidized nature of this site which is why it was targeted for coring. The Gilmore Hill cores sample an interval about 2 million years younger than the PCB and BSN cores and are thus quite different from them in that they are dominated by paleosol red beds, with only minor occurrences of the less oxidized facies. Whereas the density logs are typical in tracking grain size, the magnetic susceptibility logs show several scales of variability, which we investigated in more detail in order to understand the processes driving this variability.

We carried out preliminary isothermal remanent magnetization (IRM) experiments on a series of discrete samples to better understand the underlying mineralogical factors that control magnetic susceptibility variability in these cores. Representative samples were collected from core depths showing low, medium, or high susceptibilities based on multi-sensor core logs. Bulk mass normalized susceptibility was measured for each sample and compared to the corresponding core log measurement. Only those samples that showed good agreement between measured susceptibility and core log data were analyzed further. A hard (1.1 T) IRM was acquired in a step-wise fashion along the $z$ axis of each sample with subsequent back-field IRMs of -100 and $-300 \mathrm{mT}$ applied to further constrain the proportions of magnetic minerals with different coercivity. After reacquiring a $1.1 \mathrm{~T}$ IRM along the $z$ axis, medium coercivity $(0.4 \mathrm{mT})$ and low coercivity $(0.12 \mathrm{mT})$ IRMs were acquired along the $y$ and $x$ axes, respectively, and the samples were thermally demagnetized in a step-wise fashion (Lowrie, 1990). Results show that the highest magnetic susceptibilities in the cores are associated with coarser deposits (sandstones and siltstones) that are enriched in detrital magnetite. Some mudstones have elevated magnetic susceptibility as well but in these cases it is caused by enrichment of hematite due to pedogenesis (Fig. 5).

Results from extensive previous research on outcrops in the areas surrounding the coring sites provides an excellent opportunity to compare proxy results recovered from stratigraphically overlapping cores and outcrops to explore the potential effects of weathering on these records. Sediment color in both the Fort Union and Willwood Formations are significantly different between core and outcrop and thus is clearly affected by weathering (see discussion above and Fig. 4). Although distinctly colored strata can be identified in, and correlated between, core and outcrop, the colors in the cores are muted compared to the highly accentuated weathered colors in the outcrops. Preliminary analysis of total organic carbon and stable carbon and oxygen isotopes in organic matter and carbonate indicate very little difference between core and outcrop results, although the oxygen isotopic composition of surface carbonate nodules may be slightly lower compared to core samples potentially due to interaction with meteoric water (Fig. 6a). Preservation of organic biomolecules, however, is clearly elevated in core samples relative to outcrop sample. For instance, terpenoids, hopanes and $n$-alkanes all exhibit significantly higher concentrations in sub-surface, unweathered samples compared to outcrop samples (e.g., Fig. 6b). 


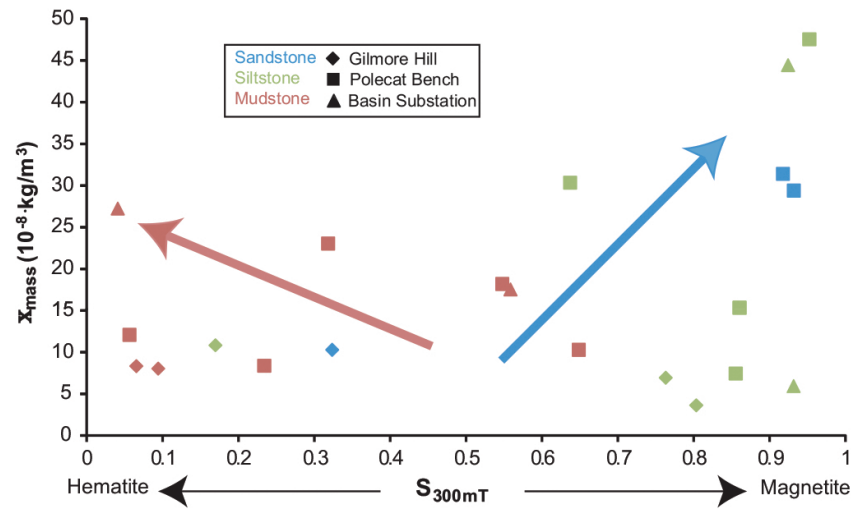

Figure 5. Magnetic susceptibility plotted against $S$ ratio $\left(S_{300 \mathrm{mT}}\right.$; Thompson and Oldfield, 1986) showing that the highest magnetic susceptibilities are associated with coarser deposits (sandstones and siltstones) enriched in detrital magnetite (higher $S$ ratios) but that some mudstones have elevated magnetic susceptibility because of enriched hematite concentrations (lower $S$ ratios) due to pedogenesis.

GDGTs (glycerol dialkyl glycerol tetraethers), compounds used as a paleotemperature proxy, were not detectable in either core or outcrop samples and were likely degraded by oxidative diagenesis and/or thermal maturation during burial. Pollen preservation is similar between core and outcrop samples of carbonaceous shales but core samples of oxidized paleosol units do produce rare sporomorphs, whereas outcrop samples of those facies tend to be barren.

\section{Outreach}

The Bighorn Basin preserves one of the most complete and fossiliferous stratigraphic sections of earth's sedimentary carapace. In collaboration with the Denver Museum of Nature and Science, we designed a multi-faceted outreach program to capitalize on this and make the basin into a natural classroom for educating the public about key scientific issues facing today's society - evolution, geological time, and climate change. To draw attention to the remarkable evolution of earth's environment and biota over long geological timescales, we are writing a small book that includes 12 landscape reconstruction paintings by illustrator Jan Vriesen (Fig. 7). This book is patterned after the successful Ancient Denvers book that capitalized on the well-studied stratigraphy and paleontology of the Denver Basin, sold more than 10000 copies, and remains one of the region's most accessible portals to paleontology and geology. The book Ancient Bighorn Basin will include a brief overview of the basin's geology featuring a stratigraphic block diagram of the basin that illustrates the filling and exhumation of the basin and the creation of the modern landscape. Each prehistoric reconstruction will be paired with photographs of formations and fossils that document the evidence used to create the

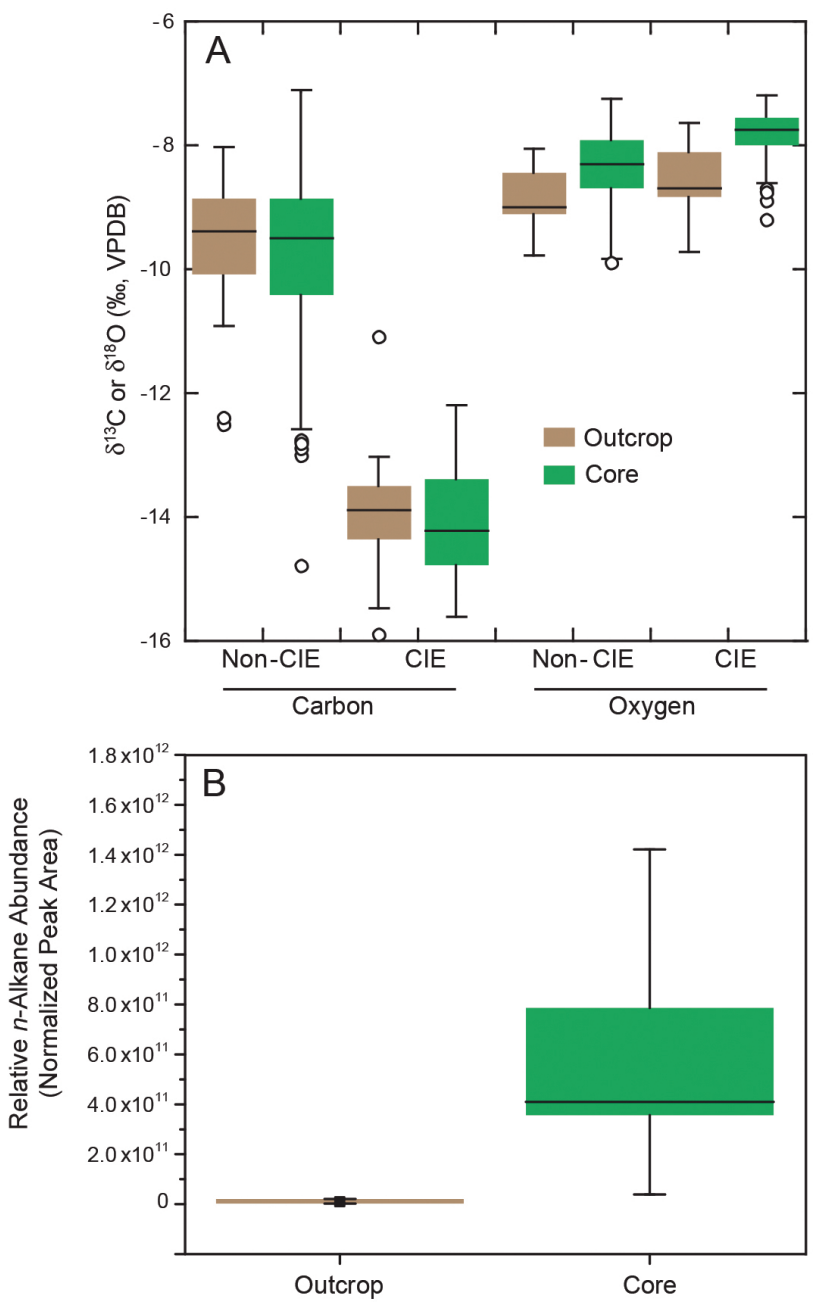

Figure 6. (A) Relative $n$-alkane abundances expressed as total FID peak area for C27, C29 and C31 n-alkanes corrected for injection ratio and mass of sediment extracted in non-PETM carbonaceous shale samples from Basin Substation core 1B (green, right) compared to adjacent outcrop samples (brown, left). $n$-Alkane peak areas in core samples are on average 60 times greater than in outcrop samples. (B) Stable carbon (left) and oxygen (right) isotope values of pedogenic carbonate samples from Polecat Bench cores $2 \mathrm{~A}$ and $2 \mathrm{~B}$ (green) compared to adjacent outcrop samples from the same beds. Samples are split between those stratigraphically within the PETM carbon isotope excursion (CIE) and those that fall outside that interval (non-CIE). Isotopic values from the cores overlap those from the outcrops quite closely with the possibility of a slight systematic offset in $\delta^{18} \mathrm{O}$ values that could be associated with minor amounts of diagenetic alteration by local meteoric fluids in the outcrop samples.

painting. Such a book should have tremendous appeal for the many tourists to the region (especially Yellowstone) and also provide, for the first time, accessible prehistory for the region's students and residents.

Continental drilling is one of the few science activities that can be watched by the public and perceived as science 


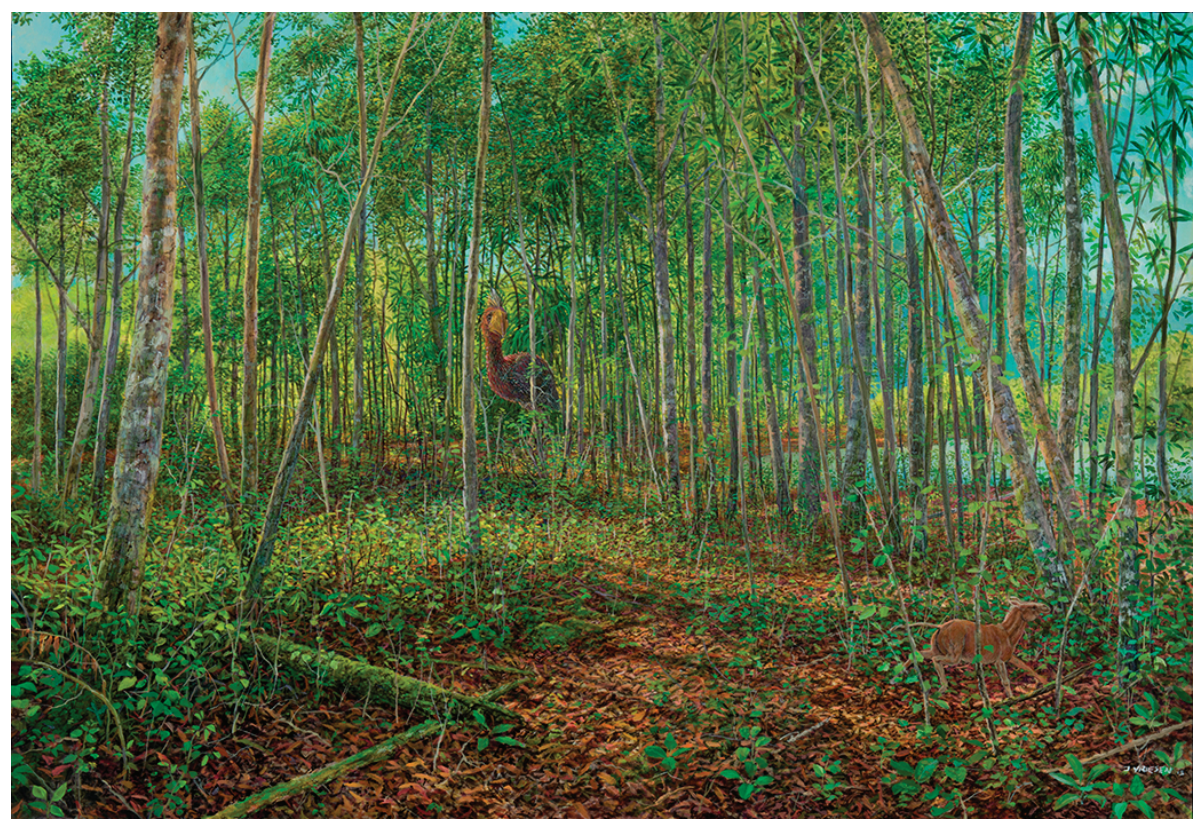

Figure 7. Eocene reconstruction scene painted by Jan Vriesen as part of BBCP outreach efforts. This is one of twelve Phanerozoic landscape reconstructions of the Bighorn Basin that Vriesen painted to increase awareness about earth-system variability over deep time and the unusually complete geological and paleontological record preserved in the basin. This scene shows an early Eocene floodplain forest with the large predatory flightless bird Diatryma (= Gastornis) in the background and the diminutive "dawn horse" horse Hyracotherium to the right.

in action. Another aspect of the BBCP outreach effort was to make live broadcasts from the Gilmore Hill drill site to schools and public audiences in the region. The Science in Action program at DMNS has pioneered the use of live twoway satellite broadcasts from field sites to classrooms. These two-way broadcasts allow live audience participation and conversations with the scientists on site. In order to have a multiplicative impact (and since the drilling was occurring during the summer when schools were out of session), we focused our program on groups of teachers so they could carry forward what they learned into their classrooms. The broadcasts were preceded by a lesson plan and informational video so participants were aware of the content and were primed to ask questions. In total we reached 173 teachers which should trickle down to well over 10000 students.

One often overlooked audience for outreach is the group of scientists who may undertake similar scientific activities in the future and may benefit from the experiences of the current project. There has been considerable recent focus on growing continental scientific drilling activity in the US to help investigate, and provide new perspectives on, some of the major ongoing questions of earth sciences (Brigham-Grette et al., 2011; Walton et al., 2009, 2010). One of the limiting factors in implementing this plan, however, has been the relatively limited number of earth scientists with relevant training and experience in continental scientific drilling as well as the lack of drilling as a common tool in the deep-time scientific culture. In order to help educate scientists who have no experience with scientific drilling but may benefit from core records in their research, we have produced a $25 \mathrm{~min}$ video about continental drilling for the scientific community. This video documents the key steps in developing and implementing a continental scientific drilling project (e.g., planning, proposal development, drilling operations, post-drilling science). The video aims to help overcome that lack of experience and familiarity by educating the community about the benefits of continental core records and describing the logistical steps that must be taken to recover them. DVDs are being provided to relevant organizations for distribution at scientific meetings and the video file has been posted on YouTube and the project website.

Aside from these formal elements of the outreach plan, we also carried out many informal activities including onsite tours with a simple informational brochure for local residents and students (e.g., geology field camps passing through), an active Facebook page that helped non-resident team members and other interested parties to keep up on drilling progress, a science blog on the Smithsonian National Museum of Natural History web page, a presentation at the local natural history museum in Worland, Wyoming, and many interviews with the press that resulted in local, national and international news items. During the Science Party in Bremen the local daily newspaper (circulation 170000 copies) became interested in the project and published an article in their science section. 


\section{Future scientific research}

The BBCP is currently in the post-drilling science phase of the project. Preliminary BBCP results were presented at a 2012 AGU special session entitled "Continental Records of Early Paleogene Hyperthermals" and at EGU 2013 in the "Major Achievements and Perspectives in Scientific Ocean and Continental Drilling" session. We expect peer-reviewed publications detailing $\mathrm{BBCP}$ results to start appearing in the next year. Given the high core recovery rates and relative ease of drilling these kinds of continental fluvial sediments, we expect the BBCP will catalyze more scientific drilling activity in the relatively expanded stratigraphic records of intermontane basinal settings like the Bighorn Basin.

\section{The BBCP Science Team}

R. Acks, A. Baczynski, C. Belcher, G. Bowen, K. Brady, W. Clyde, M. Collinson, A. D’Ambrosia, E. Denis, K. Freeman, P. Gingerich, G. Harrington, P. Jardine, K. Johnson, M. Kraus, B. Maibauer, F. McInerney, A. Noren, J. Riedel, U. Röhl, D. Schnurrenberger, S. Schouten, K. Tsukui, J. Weijers, G. Welter, T. Westerhold, S. Wing, F. Wittkopp, and A. Wood

Acknowledgements. We thank the Churchill family and Mike Bies for logistical support during drilling, our various institutional partners (BLM, ExxonMobil, DOSECC, ICDP) for their cooperation, Dave Baysinger and Jan Vriesen for their contributions to our outreach program, and Tristan Amaral for drafting of the final lithological logs. H. Kuhlmann, L. Schnieders, M. Böthig, V. Lukies, W. Hale, A. Wülbers, H. Wallrabe-Adams (all Bremen) and, R. Conze (Potsdam) provided valuable assistance to the science team during core processing at the Bremen Core Repository. This project is funded by NSF collaborative grants 0958821 , 0958717, 0958975, 0958904, 1261312, 0958951, 0958583, and by the Deutsche Forschungsgemeinschaft (DFG).

Edited by: T. Wiersberg

Reviewed by: C. Koeberl and one anonymous referee

\section{References}

Abdul-Aziz, H., Hilgen, F. J., van Luijk, G. M., Sluijs, A., Kraus, M. J., Pares, J. M., and Gingerich, P. D.: Astronomical climate control on paleosol stacking patterns in the upper Paleocene-lower Eocene Willwood Formation, Bighorn Basin, Wyoming, Geology, 36, 531-534, 2008.

Abels, H. A., Clyde, W. C., Gingerich, P. D., Hilgen, F. J., Fricke, H. C., Bowen, G. J., and Lourens, L. J.: Terrestrial carbon isotope excursions and biotic change during Palaeogene hyperthermals, Nat. Geosci., 5, 326-329, 2012.

Abels, H. A., Kraus, M. J., and Gingerich, P. D.: Precession-scale cyclicity in the fluvial lower Eocene Willwood Formation of the Bighorn Basin, Wyoming (USA), Sedimentology, 60, 14671483, doi:10.1111/sed.12039, 2013.
Agnini, C., Macrì, P., Backman, J., Brinkhuis, H., Fornaciari, E., Giusberti, L., Luciani, V., Rio, D., Sluijs, A., and Speranza, F.: An early Eocene carbon cycle perturbation at $\sim 52.5 \mathrm{Ma}$ in the Southern Alps: chronology and biotic response, Paleoceanography, 24, PA2209, doi:10.1029/2008PA001649, 2009.

Bowen, G. J., Koch, P. L., Gingerich, P. D., Norris, R. D., Bains, S., and Corfield, R. M.: A high-resolution isotope stratigraphy across the Paleocene-Eocene boundary at Polecat Bench, Wyoming, in: Paleocene-Eocene Stratigraphy and Biotic Change in the Bighorn and Clarks Fork Basins, edited by: Gingerich, P. D., Wyoming, Univ. Mich. Pap. Paleontol., 33, 78-88, 2001.

Bowen, G. J., Bralower, T. J., Delaney, M. L., Dickens, G. R., Kelly, D. C., Koch, P. L., Kump, L. R., Meng, J., Sloan, L. C., Thomas, E., Wing, S. L., and Zachos, J. C.: Eocene hyperthermal event offers insight into greenhouse warming, Eos Trans. Am. Geophys. Union, 87, 165-169, 2006.

Bown, T. M., Rose, K. D., Simons, E. L., and Wing, S. L.: Distribution and stratigraphic correlation of upper Paleocene and lower Eocene fossil mammal and plant localities of the Fort Union, Willwood, and Tatman formations, southern Bighorn Basin, Wyoming, US Geol. Surv. Prof. Pap., 1540, 1-103, 1994.

Brigham-Grette, J., Walton, A., Cohen, A., and Rack, F.: Toward a Strategic Plan for U.S. Continental Scientific Drilling: Into the New Decade, DOSECC Work. Publ., 3, 1-27. http://www.dosecc.org/images/stories/Workshops/DOSECC_ Workshop_Report_2011_sm.pdf, 2011.

Chew, A. E.: Paleoecology of the early Eocene Willwood mammal fauna from the central Bighorn Basin, Wyoming, Paleobiology, 35, 13-31, 2009.

Clyde, W. C. and Gingerich, P. D.: Mammalian community response to the latest Paleocene thermal maximum: An isotaphonomic study in the northern Bighorn Basin, Wyoming, Geology, 26, 1011-1014, 1998.

Gingerich, P. D.: History of early Cenozoic vertebrate paleontology in the Bighorn Basin, Early Cenozoic paleontology and stratigraphy of the Bighorn Basin, Wyoming, in: Early Cenozoic paleontology and stratigraphy of the Bighorn Basin, edited by: Gingerich, P. D., Wyoming, Univ. Mich. Pap. Paleontol., 24, 7-24, 1980.

Gingerich, P. D.: New earliest Wasatchian mammalian fauna from the Eocene of northwestern Wyoming: Composition and diversity in a rarely sampled high-floodplain assemblage, Univ. Mich. Pap. Paleontol., 28, 1-97, 1989.

Gingerich, P. D.: Environment and evolution through the Paleocene-Eocene thermal maximum, Trends Ecol. Evol., 21, 246-253, 2006.

Gingerich, P. D. and Clyde, W. C.: Overview of mammalian biostratigraphy in the Paleocene-Eocene Fort Union and Willwood Formations of the Bighorn and Clarks Fork Basins, in: Paleocene-Eocene Stratigraphy and Biotic Change in the Bighorn and Clarks Fork Basins, edited by: Gingerich, P. D., Wyoming, Univ. Mich. Pap. Paleontol., 33, 1-14, 2001.

Koch, P. L., Zachos, J. C., and Gingerich, P. D.: Correlation between isotope records in marine and continental carbon reservoirs near the Palaeocene/Eocene boundary, Nature, 358, 319-322, 1992.

Kopp, R. E., Raub, T. D., Schumann, D., Vali, H., Smirnov, A. V., and Kirschvink, J. L.: Magnetofossil spike during the Paleocene-Eocene thermal maximum: Ferromagnetic resonance, rock magnetic, and electron microscopy evidence from An- 
cora, New Jersey, United States, Paleoceanography, 22, PA4103, doi:10.1029/2007PA001473, 2007.

Lee, Y. S. and Kodama, K.: A possible link between the geomagnetic field and catastrophic climate at the Paleocene-Eocene thermal maximum, Geology, 37, 1047-1050, 2009.

Lippert, P. C. and Zachos, J. C.: A biogenic origin for anomalous fine-grained magnetic material at the Paleocene-Eocene boundary at Wilson Lake, New Jersey, Paleoceanography, 22, PA4104, doi:10.1029/2007PA001471, 2007.

Lourens, L. J., Sluijs, A., Kroon, D., Zachos, J. C., Thomas, E., Röhl, U., Bowles, J., and Raffi, I.: Astronomical pacing of late Palaeocene to early Eocene global warming events, Nature, 435, 1083-1087, 2005.

Lowrie, W.: Identification of ferromagnetic minerals in rocks by coercivity and unblocking temperature properties, Geophys. Res. Lett., 17, 159-162, 1990.

Magioncalda, R., Dupuis, C., Smith, T., Steurbaut, E., and Gingerich, P. D.: Paleocene-Eocene carbon isotope excursion in organic carbon and pedogenic carbonate: Direct comparision in a continental stratigraphic section, Geology, 32, 553-556, 2004.

McInerney, F. A. and Wing, S. L.: The Paleocene-Eocene Thermal Maximum: A perturbation of carbon cycle, climate, and biosphere with implications for the future, Annu. Rev. Earth Pl. Sc., 39, 489-516, 2011.

Schankler, D. M.: Faunal zonation of the Willwood Formation in the central Bighorn Basin, Wyoming, in: Early Cenozoic paleontology and stratigraphy of the Bighorn Basin, edited by: Gingerich, P. D., Wyoming, Univ. Mich. Pap. Paleontol, 24, 99-114, 1980.

Schumann, D., Raub, T. D., Kopp, R. E., Guerquin-Kern, J.-L., Wu, T.-D., Rouiller, I., Smirnov, A. V., Sears, S. K., Lücken, U., and Tikoo, S. M.: Gigantism in unique biogenic magnetite at the Paleocene-Eocene Thermal Maximum, P. Natl. Acad. Sci. USA, 105, 17648-17653, 2008.

Secord, R., Gingerich, P. D., Lohmann, K. C., and MacLeod, K. G. N.: Continental warming preceding the Palaeocene-Eocene thermal maximum, Nature, 467, 955-958, 2010.

Sexton, P. F., Norris, R. D., Wilson, P. A., Pälike, H., Westerhold, T., Röhl, U., Bolton, C. T., and Gibbs, S.: Eocene global warming events driven by ventilation of oceanic dissolved organic carbon, Nature, 471, 349-352, 2011.

Sluijs, A., Schouten, S., Pagani, M., Woltering, M., Brinkhuis, H., Sinninghe Damsté, J. S., Dickens, G. R., Huber, M., Reichart, G.-J., Stein, R., Matthiessen, J., Lourens, L. J., Pedentchouk, N., Backman, J., Moran, K., and the Expedition 302 Scientists: Subtropical Arctic Ocean temperatures during the Palaeocene/Eocene thermal maximum, Nature, 441, 610-613, 2006.
Sluijs, A., Bowen, G. J., Brinkhuis, H., Lourens, L. J., and Thomas, E.: The Palaeocene-Eocene Thermal Maximum super greenhouse: biotic and geochemical signatures, age models and mechanisms of global change, in: Deep-Time Perspectives on Climate Change: Marrying the Signal from Computer Models and Biological Proxies, edited by: Williams, M., Haywood, A. M., Gregory, F. J., and Schmidt, D. N., The Micropalaeontological Society, Special Publications, The Geological Society, London, 323349, 2007.

Thomas, D. J., Zachos, J. C., Bralower, T. J., Thomas, E., and Bohaty, S.: Warming the fuel for the fire: Evidence for the thermal dissociation of methane hydrate during the Paleocene-Eocene thermal maximum, Geology, 30, 1067-1070, 2002.

Thomas, E., Röhl, U., Monechi, S., Westerhold, T., Balestra, B., and Morelli, G.: An early Eocene hyperthermal event at $~ 52.5 \mathrm{Ma}$, Clim. Biota Early Paleogene, Vol. Abstr., p. 136, 2006.

Thomas, E. and Zachos, J. C.: Was the late Paleocene thermal maximum a unique event?, GFF, 122, 169-170, 2000.

Thompson, R. and Oldfield, F.: Environmental Magnetism, Allen \& Unwin, Limited, London, 227 p., 1986.

Walton, A., Miller, K. G., Koeberl, C., Shervais, J., Colman, S., and Hickman, S.: The Future of Continental Scientific Drilling: U.S. Perspective, DOSECC Work. Publ., 1, 1-58, http://www.dosecc.org/images/stories/DOSECC_pdfs/ Future_of_CSD_FINAL_Report_-_small1.pdf, 2009.

Walton, A., Brigham-Grette, J., Shervais, J., and Snyder, W.: Developing the U.S. initiative in continental scientific drilling, DOSECC Work. Publ., 2, 1-43, http://www.dosecc.org/images/ stories/DOSECC_pdfs/Workshop_2010_Final_J913sm.pdf, 2010 .

Wing, S. L.: Paleocene/Eocene floral change in the Bighorn Basin, Wyoming, in: Late Paleocene-early Eocene climatic and biotic evolution, edited by: Aubry, M. P., Lucas, S., and Berggren, W. A., Columbia University Press, New York, 380-400, 1998.

Wing, S. L., Harrington, G. J., Smith, F. A., Bloch, J. I., Boyer, D. M., and Freeman, K. H.: Transient floral change and rapid global warming at the Paleocene-Eocene boundary, Science, 310, 993996, 2005.

Zachos, J. C., Röhl, U., Schellenberg, S. A., Sluijs, A., Hodell, D. A., Kelly, D. C., Thomas, E., Nicolo, M., Raffi, I., Lourens, L. J., McCarren, H., and Kroon, D.: Rapid acidification of the ocean during the Paleocene-Eocene thermal maximum, Science, 308, 1611-1615, 2005.

Zeebe, R. E. and Zachos, J. C.: Long-term legacy of massive carbon input to the Earth system: Anthropocene vs. Eocene, Phil. Trans. R. Soc. A, 371, 20120006, doi:10.1098/rsta.2012.0006, 2013. 